\title{
An Analysis of Wenckebach Periodicity during Atrial Pacing
}

\author{
Michio Okada, M.D.
}

\begin{abstract}
SUMMARY
Seventy-six atrial pacing induced Wenckebach periods in 20 patients were analyzed. They were divided into 5 types according to the manner of increment change of $\mathrm{P}^{\prime} \mathrm{V}$ prolongation. Fifty-four $\%$ of the periods were atypical (Types II-V). There was a significant increase in the incidence of atypical periods as the length of the periods increased. The recovery curve of the A-V node was obtained by plotting $\mathrm{P}^{\prime} \mathrm{V}$ against preceding $\mathrm{VP}^{\prime}$. The curve was convex and the slope became greater than 45 degrees near the absolute refractory period in the majority of the cases, although there was 1 case in which the slope was less than 45 degrees throughout the curve. The $\mathrm{P}^{\prime} \mathrm{V}$ interval was found to be determined mainly by the preceding $\mathrm{VP}^{\prime}$ interval. The mechanism by which these different types of Wenckebach periods develop can be explained by the relationship between the shape of the recovery curve and the pacing rate. The types II, III, and IV periods which have been dealt with as atypical periods were understood to develop by the same mechanism as type I (typical) periods.
\end{abstract}

\section{Additional Indexing Words:}

Atypical Wenckebach period

A-V block

Atrial pacing

Recovery curve His bundle electrogram Increment

$I^{1}$

$\mathrm{N}$ a typical Wenckebach type block at the A-V node, the increments of $\mathrm{P}-\mathrm{R}$ interval prolongation decrease progressively. Wenckebach himself has already suggested that departures from typical periodicity were frequent in the human heart. Especially in the Wenckebach period (WP) with a high conduction ratio, it is widely known that the increment change does not follow the typical pattern.

Since the introduction of atrial pacing (AP) and His bundle electrogram (HBE) for the study of the A-V conduction system, WPs during atrial pacing have been reviewed by some authors. ${ }^{1)-4)}$ They found that atypical periods were very common.

On reviewing the $\mathrm{HBE}$ recordings of WPs induced by $\mathrm{AP}$, it was found that these WPs can be divided into 5 types on the bases of the manner of the

From the Department of Internal Mecicine, Saiseikai Central Hospital, Mita, Minato-ku, Tokyo. Received for publication April 22, 1977. 
change in the increments of $A-V$ conduction time. The purpose of the present study is to evaluate the frequency of each type of the WPs and to study the underlying mechanism of these types which at present still remains to be explored.

\section{Materials and Methods}

All medical data were taken from the patients seen at Saiseikai Central Hospital between 1973 and 1975. Of the 43 patients who underwent the HBE study for the assessment of their conduction system, 20 patients developed, as a whole, $76 \mathrm{~A}-\mathrm{V}$ WPs with a conduction ratio of $4: 3$ or greater during atrial pacing. These 20 patients and their 76 WPs were analyzed (Table I).

HBEs were recorded using the previously described techniques. ${ }^{5)}$ A tripolar USCI electrode catheter was introduced percutaneously through the right femoral

Table I. Glinical and Electrocardiographic Features of Patients Studied

\begin{tabular}{|c|c|c|c|c|c|}
\hline $\begin{array}{l}\text { Case } \\
\text { No. }\end{array}$ & Patients & Age & $\begin{array}{l}\text { Clinical } \\
\text { Diagnosis }\end{array}$ & ECG Findings & $\begin{array}{l}\text { Type of } \\
\text { Recovery } \\
\text { Curve }\end{array}$ \\
\hline 1 & H. N. & 25 & A.S. H. D. & Old M. 1. & A \\
\hline 2 & T. H. & 65 & A.S. H. D. & L. B. B. B., V.P. C. & B \\
\hline 3 & S. K. & 32 & N. A. H. D. & L. V.H. & 一 \\
\hline 4 & Y.I. & 67 & S. S. S. & SA Block & - \\
\hline 5 & S.S. & 42 & N.A. H. D. & Sinus Bradycardia & B \\
\hline 6 & $\mathbf{S}, \mathbf{K}$. & 71 & H, C. V, D. & L. V.H., S. B. & - \\
\hline 7 & K. N. & 36 & N.A. H. D. & R.B. B. B. with L. A. D. & B \\
\hline 8 & S. M. & 31 & S. S.S. & S. B., lst degree H.B. & - \\
\hline 9 & A. E. & 67 & S. S. S. & S. B. & - \\
\hline 10 & Y.T. & 21 & W. P. W. & W. P. W., L.V.H. & - \\
\hline 11 & K. H. & 76 & S. S. S. & SA Block, A. P. C., L. V.H. & - \\
\hline 12 & H. S. & 22 & H.C. V.D. & R.B.B.B. & - \\
\hline 13 & Z.N. & 59 & H.C. V. D. & S. B. & - \\
\hline 14 & K. K. & 24 & N. A. H. D. & A-V Dissociation & - \\
\hline 15 & $\mathrm{~K} . \mathrm{O}$. & 35 & S. S. S. & SA Block, L. V.H. & - \\
\hline 16 & T. O. & 69 & S. S. S. & SA Block, R. B. B. B. & $\mathrm{B}$ \\
\hline 17 & K. O. & 68 & H.C. V. D. & S. B., A. P. C. & - \\
\hline 18 & T. W. & 63 & P. M. D. & L. V.H., S.B. & $\mathrm{B}$ \\
\hline 19 & T. O. & 15 & N.A.H.D. & R. B. B. B. & $\mathrm{B}$ \\
\hline 20 & S. A. & 57 & H.C. V.D. & L. V.H., Wenckebach & $\mathbf{B}$ \\
\hline
\end{tabular}

A. S. H, D. = Arteriosclerotic heart disease, N. A, H. D. = No apparent heart disease, S. S. S. = Sick sinus syndrome, H.C. V. D. $=$ Hypertensive cardiovascular disease, W. P. W. = Wolff-ParkinsonWhite syndrome, P.M. D. = Primary myocardial disease M. I.= Myocardial infarction, L. B. B. B. $=$ Left bundle branch block, V.P.C. =Ventricular premature contraction, L. V. H. =Left ventricular hypertrophy, S. B.=Sinus bradycardia, R. B. B. B.= Right bundle branch block, L. A. D. $=$ Left axis deviation, A. P. C. =Atrial premature contraction, H. B. = Heart block 


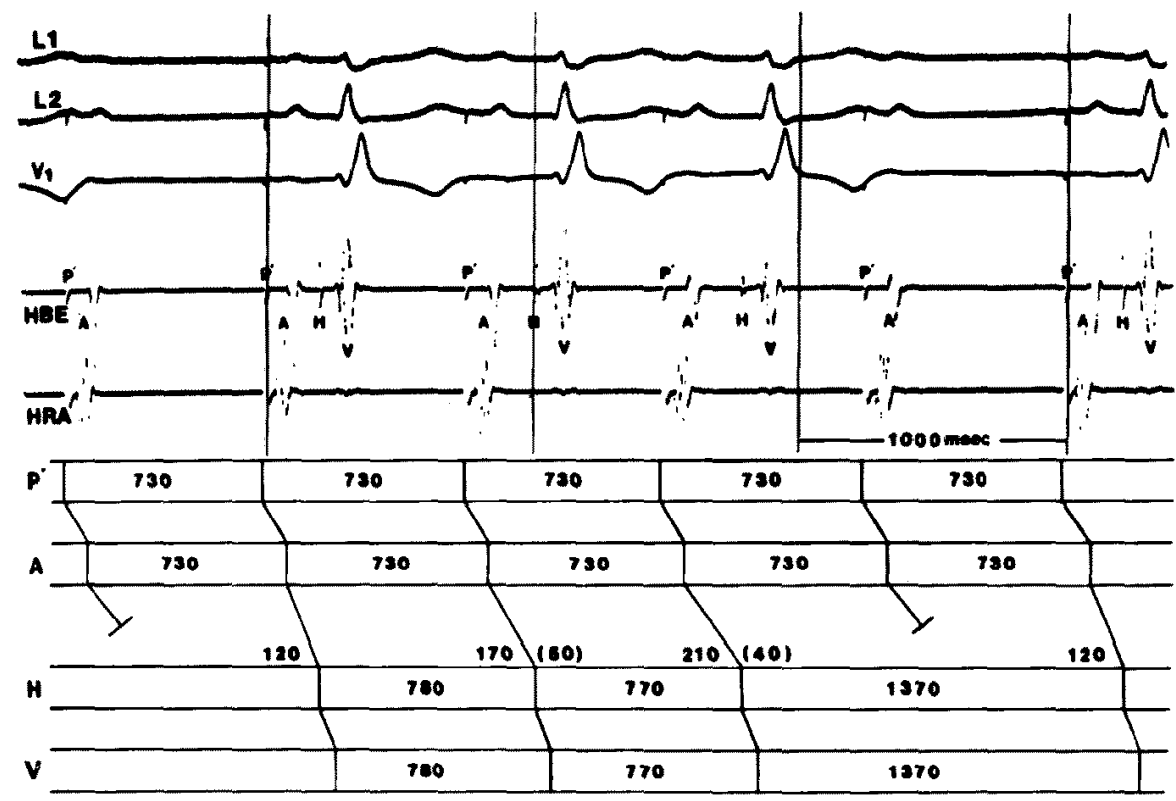

Fig. 1. Simultaneous standard leads $\mathrm{I}$, II, and $\mathrm{V}_{1}$, a His bundle electrogram (HBE), high right atrial electrogram (HRA), and a ladder diagram based on the tracing that show a Wenckebach period with a conduction ratio of $4: 3$ during atrial pacing.

vein and positioned across the tricuspid valve to record the HBE. An additional quadrapolar electrode catheter was introduced through the same vein and positioned in close proximity to the sinus node. The distal pair of electrodes were used for AP and the proximal pair were used to record the high atrial electrogram. Electrocardiograms from 3 leads (usually I, II, $V_{1}$ ), and atrial and His bundle electrograms with filters set at a frequency response of $40-500 \mathrm{~Hz}$ were recorded simultaneously on a multichannel recorder (Electronics for Medicine, DR-12) at a paper speed of $100 \mathrm{~mm} / \mathrm{sec}$ (Fig. 1). The pacing rate was set at $5-10$ pulses/min above the spontaneous rate at first, and pacing was continued for $30-60 \mathrm{sec}$. With $2 \mathrm{~min}$ intervals, the pacing rate was increased by $10-20$ pulses $/ \mathrm{min}$. And the maximum pacing rate was $140 / \mathrm{min}$.

The $\mathrm{P}^{\prime} \mathrm{A}, \mathrm{AH}, \mathrm{HV}, \mathrm{P}^{\prime} \mathrm{V}$, and $\mathrm{VP}^{\prime}$ were measured to the nearest $5 \mathrm{msec}$. In the 20 cases, $\mathrm{HV}$ and $\mathrm{P}^{\prime} \mathrm{A}$ intervals did not change appreciably. This means that the observations regarding $\mathrm{AH}$ and $\mathrm{P}^{\prime} \mathrm{V}$ intervals could be considered as being interchangeable. Therefore the $\mathrm{P}^{\prime} \mathrm{V}$ interval was substituted for the $\mathrm{A}-\mathrm{V}$ conduction time in this report.

These $76 \mathrm{WPs}$ werc divided into 5 types according to the following criteria (Fig. 2). Type I: Typical Wenckebach period. The increments of the $P^{\prime} V$ interval prolongation diminish progressively. Type II: The increments decrease at first, then increase before the dropped beat. Type III: The increments increase progressively. Type IV: The increments are constant. Type V: The increment becomes negative before the dropped beat. The increments in the long 


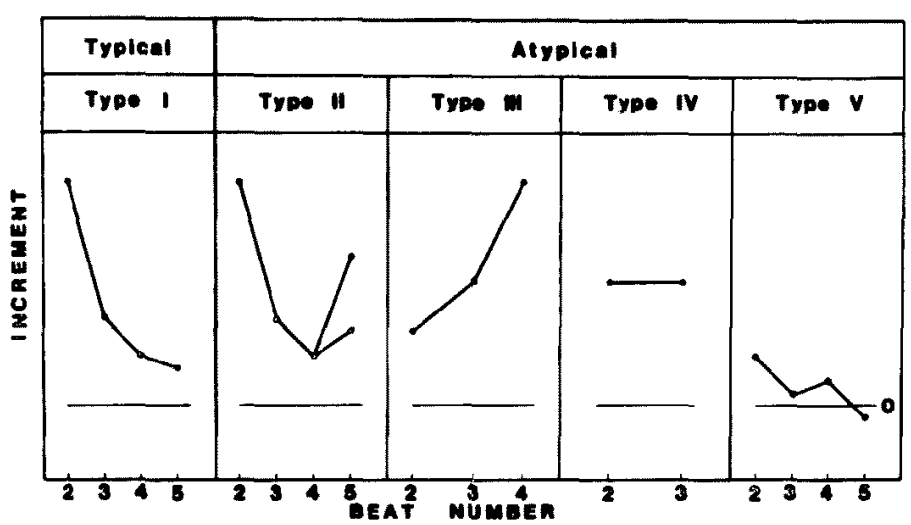

Fig. 2. Type of Wenckebach periodicity.

periods fluctuated a little irregularly in some cases, and in these cases, the fine fluctuations were neglected. The reason why these fluctuations were neglected will be discussed later.

Furthermore, the so called recovery curve of $\mathrm{A}-\mathrm{V}$ junction was described in several cases by plotting the interrelationship between the $\mathrm{P}^{\prime} \mathrm{V}$ and preceding $\mathrm{VP}^{\prime}$ intervals graphically, and the shape of this curve and the relationship between the shape of this curve and the type of WP were studied.

\section{Results}

1. Frequency of each type of Wenckebach period

Table II shows the number of each type of WP and the A-V conduction ratio at which these observations were made. Of the 76 WPs, 35 WPs $(46 \%)$ were type I, $25(33 \%)$ were type II, $13(17 \%)$ were type III, and 2 were type

Table II. Frequency of Each Type of Periods

\begin{tabular}{c|c|c|c|c|c}
\hline $\begin{array}{c}\text { Conduction } \\
\text { Ratio }\end{array}$ & Type I & Type II & Type III & Type IV & Type V \\
\hline $4: 3$ & 25 & & 9 & 2 & \\
$5: 4$ & 7 & 9 & 2 & & \\
$6: 5$ & 2 & 4 & 2 & & \\
$7: 6$ & & 1 & & & \\
$8: 7$ & 1 & 2 & & & \\
$9: 8$ & & 2 & & & \\
$10: 9$ & & 3 & & & \\
$12: 11$ & & 1 & & & \\
$15: 14$ & & 1 & & & \\
$17: 16$ & & 25 & 13 & 2 & \\
\hline Total & 35 & & & & \\
\end{tabular}




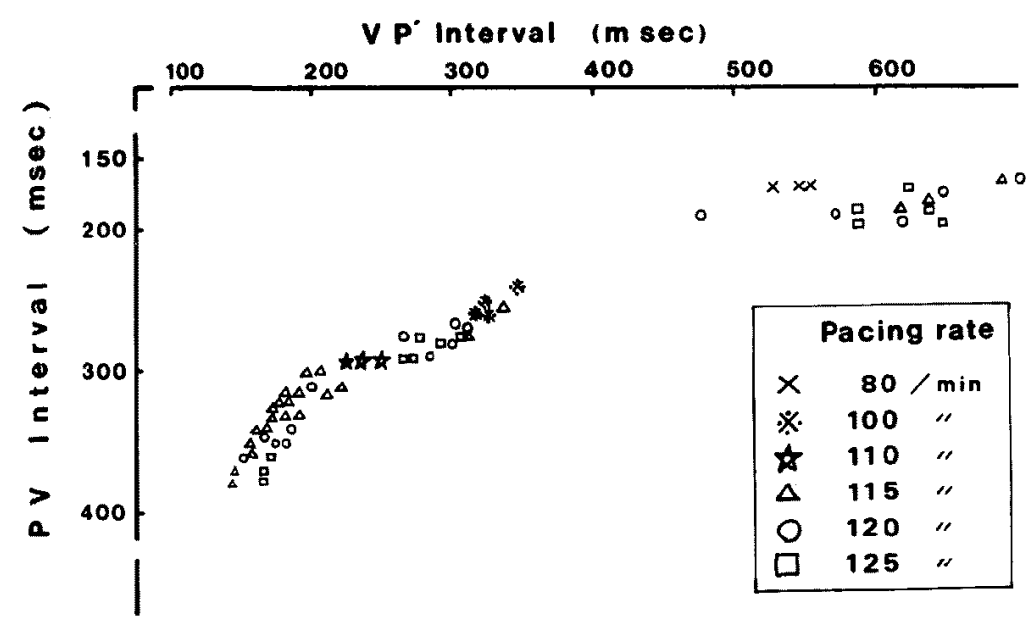

Fig. 3. Recovery curve of $A-V$ conductivity derived from tracing the relationship between $P^{\prime} V$ and $V P^{\prime}$.

IV, while 1 was type $V$. Of the 36 periods with conduction ratios of $4: 3$, 25 periods $(69 \%)$ were type I. Of the $5: 4$ periods, type II was more common than type I. In the WPs with a conduction ratio of $7: 6$ or greater, all but 2 WPs were type II. Type I was found to be uncommon in WPs with a high conduction ratio. But there was 1 type I WP with a conduction ratio of $8: 7$. No distinct relationship was found between the type of WP and pacing rate, the underlying disease, and the HBE findings at rest.

2. Recovery curve of the A-V junction

In the cases number $1,2,5,7,16,18,19$, and 20 , many WPs with various conduction ratios were found to occur in individual cases. In each of these cases the $\mathrm{P}^{\prime} \mathrm{V}$ interval was plotted against its preceding $\mathrm{VP}^{\prime}$ interval as shown in Fig. 3. The points which represent this relationship at the different pacing rates and the periods with various conduction ratios, when plotted together, describe a curve as a whole. This curve will be called the recovery curve (RG) in this paper, because it seems to represent the state of recovery of the $A-V$ junction. The shape of the $R C$ was convex. The slope becomes more than 45 degrees when the curve comes near the absolute refractory period except for case number 1 , in which the slope remained less than 45 degrees throughout the curve. In this paper, the former type of the recovery curve is called a type A and the latter type B (Figs. 4 and 5). The relationship between the shape of the $\mathrm{RC}$ and the type of WP was assumed to have the following tendency. In patients with type " $\mathrm{B}$ " $\mathrm{RG}$, the type of WP was type $I$ at any conduction ratio (Fig. 5). On the other hand, in patients with type "A " RC, WPs with low conduction ratios had a tendency 


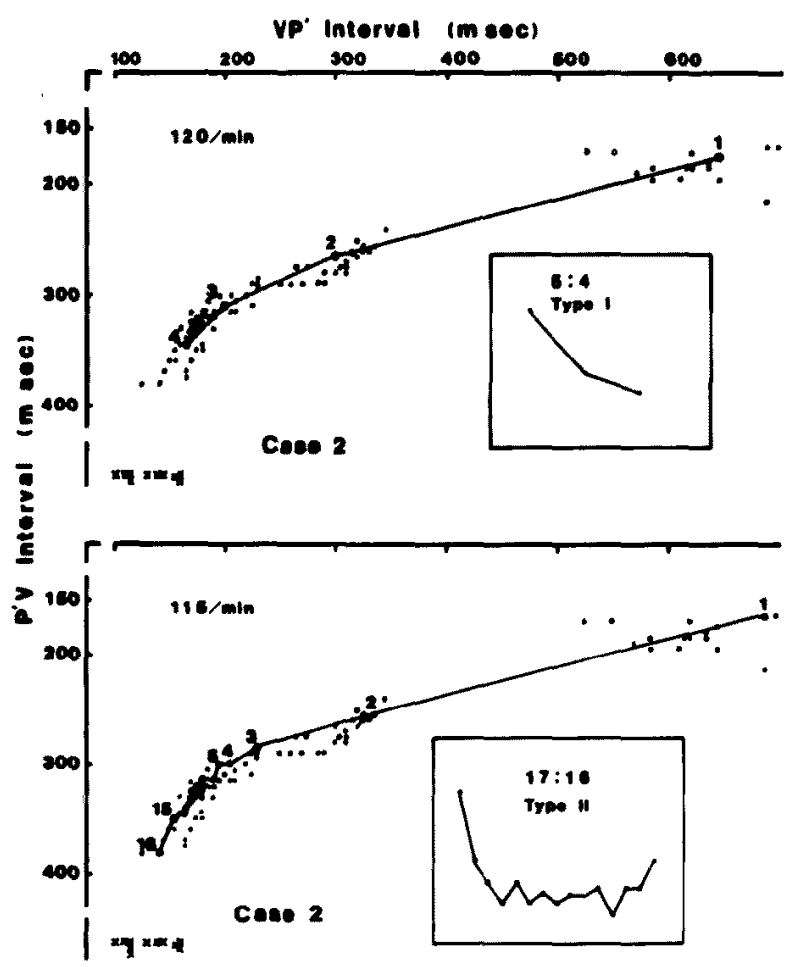

Fig. 4. A recovery curve of type A.

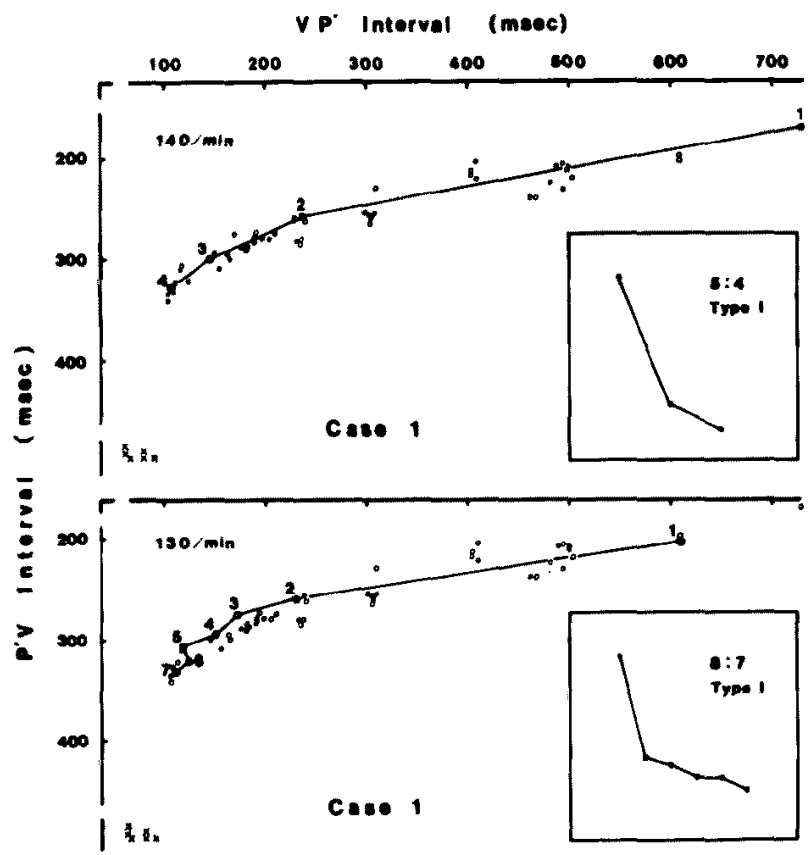

Fig. 5. A recovery curve of type B. 


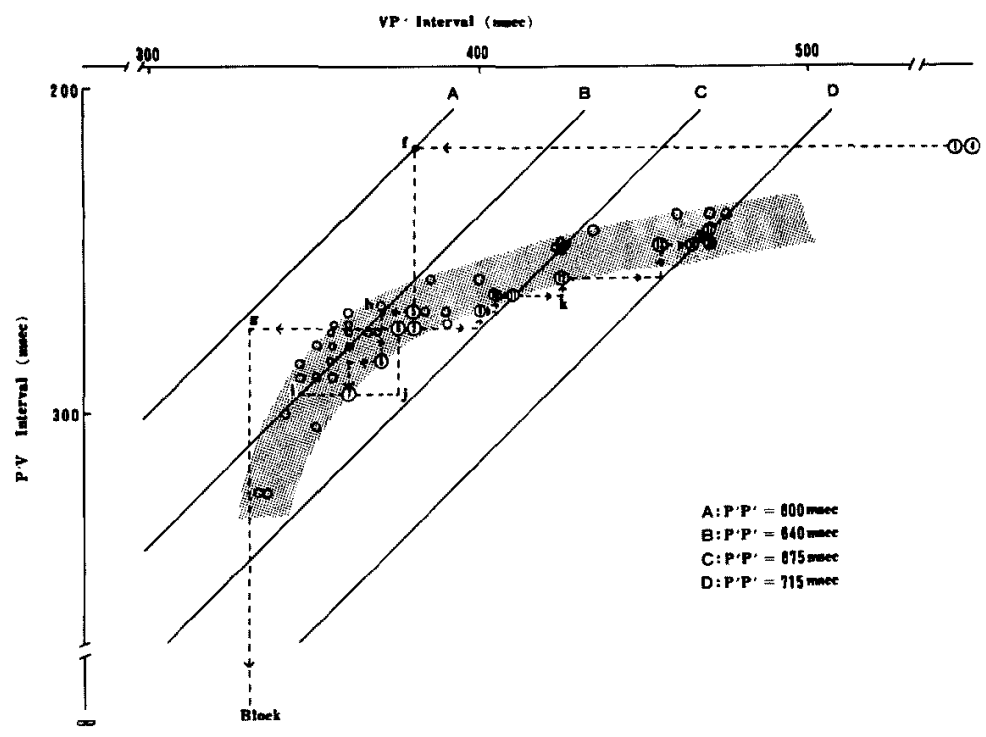

Fig. 6. The recovery curve of case number 20 .

to become type I (Fig. 4), but WPs with high conduction ratios usually became type II (Fig. 4).

In case number 20 , the pacing interval was changed every several seconds by about $40 \mathrm{msec}$ by changing the pacing rate. And all $\mathrm{P}^{\prime} \mathrm{V}$ intervals were plotted against their preceding $\mathrm{VP}^{\prime}$ intervals as shown in Fig. 6 . The $\mathrm{P}^{\prime} \mathrm{P}^{\prime}$ interval is the sum of the $\mathrm{P}^{\prime} \mathrm{V}$ and the following $V \mathrm{P}^{\prime}$. i.e. $\mathrm{P}^{\prime} \mathrm{P}^{\prime}=\mathrm{P}^{\prime} \mathrm{V}+\mathrm{VP}^{\prime}$. And this relationship is represented graphically by a straight diagonal line with a slope of 45 degrees. At the higher pacing rate, this line moves to the right as is shown from line $\mathrm{A}$ to line $\mathrm{D}$ in Fig. 6. The atrial pacing was started with a pacing interval of $600 \mathrm{msec}$. The first $\mathrm{P}^{\prime} \mathrm{V}$ interval was $220 \mathrm{msec}$ represented by point (1). The next $\mathrm{VP}^{\prime}$ interval was represented by the intersection of the horizontal line from point (1) and the line A (point $f$ ). At this $\mathrm{VP}^{\prime}$ interval, the next $\mathrm{P}^{\prime} \mathrm{V}$ interval became $275 \mathrm{msec}$, as represented by point (2). Since the next beat was again at the control of the same $\mathrm{P}^{\prime} \mathrm{P}^{\prime}$ interval, the next VP' interval was represented by point " $g$ " which was the intersection of the horizontal line from point (2) and the line A. Since there is usually some measuring error and the $\mathrm{P}^{\prime} \mathrm{P}^{\prime}$ interval did not change completely to a new interval when the pacing rate was changed, the points " $g$ ", " $\mathrm{j}$ ", and " $k$ " were not on the diagonal line. At the $\mathrm{VP}^{\prime}$ interval represented by point " $\mathrm{g}$ ", $\mathrm{P}$ ' was blocked. The first $\mathrm{P}^{\prime}$ after the block was conducted at the $\mathrm{P}^{\prime} \mathrm{V}$ interval of $220 \mathrm{msec}$, point (4). The pacing interval was changed to $640 \mathrm{msec}$ on the way to point (6) from point (5), then the next VP' interval following point (5) was represented by the point " $h$ " which was the inter- 
section of the horizontal line from point (5) and line B instead of line A. Since the next 2 beats were at the control of the same $\mathrm{P}^{\prime} \mathrm{P}^{\prime}$ interval, the $\mathrm{P}^{\prime} \mathrm{V}$ and $\mathrm{VP}^{\prime}$ followed the dotted arrows to point (7). From point (7), the $\mathrm{P}^{\prime} \mathrm{P}^{\prime}$ interval was changed to 675 msec. Then the next $V P^{\prime}$ was point " $\mathrm{j}$ " instead of point " $\mathrm{i}$ ". Since the $\mathrm{VP}^{\prime}$ became longer, the $\mathrm{P}$ ' $\mathrm{V}$ became shorter, point (B). The next 3 beats points (9), (10), and (11) were under the control of the same pacing interval. From point (11), the $\mathrm{P}^{\prime} \mathrm{P}^{\prime}$ was changed to 715 mesc. The $\mathrm{P}^{\prime} \mathrm{V}$ and $\mathrm{VP}^{\prime}$ followed in the same manner from points (12) to (17). Therefore, the points which represent the relationship of the $\mathrm{P}^{\prime} \mathrm{V}$ and the preceding $\mathrm{VP}^{\prime}$ interval are gathered together within a particular narrow range and produced the curvilineal line as shown in Fig. 6.

\section{Discussion}

The term " atypical" in WP has been applied when the manner of the increment change is atypical ${ }^{2)-4), 6)}$ or when the mechanism of the block or the site where the block develops is atypical. ${ }^{1,7)}$ In this paper only atypical WPs with the former meaning are discussed.

Denes et al first quantitated the frequency of typical and atypical WPs in patients with both spontaneous and pacing induced WPs. ${ }^{2)}$ In their study, $66 \%$ of pacing induced WPs and $86 \%$ of the spontancous WPs were atypical. WPs with a conduction ratio greater than 6:5 were all atypical. Ito et al also reported the frequency of typical and atypical WPs in the pacing induced WPs. ${ }^{3)}$ Seventy percent were atypical and WPs with conduction ratios greater than 5:4 were all atypical. In the present study, 54\% of the WPs were atypical. All of the WPs with a ratio greater than 7:6 were atypical except for 1 WP. Although only one typical period with a high conduction ratio was found, it is an important factor in that neither Denes nor Ito in their research have found a typical period with a high conduction ratio. This finding will be considered again later on in this discussion.

In those cases in which many WPs with various conduction ratios were observed under different pacing rates, the $\mathrm{P}^{\prime} \mathrm{V}$ interval was plotted against its preceding $V \mathrm{P}^{\prime}$ interval. It was shown that these points gathered together within a particular range described a curvilinear line representing the state of recovery in the A-V junction (Figs. 3, 4, 5 and 6). Especially in case number 20 (Fig. 6), even when the VP' interval was changed abruptly and without regularity by changing the pacing rate during continuous pacing, the poins representing the relationship of $\mathrm{P}^{\prime} \mathrm{V}$ and $V \mathrm{P}^{\prime}$ were still on the same curve. And furthermore, it was found that the points could go backward on the same line under certain condition as shown by points (7) through (17) in 
Fig. 6. These findings strongly suggest that the $P^{\prime} \mathrm{V}$ interval is determined mainly by the preceding $V P^{\prime}$ interval i.e. $P^{\prime} V=f\left(V P^{\prime}\right)$. The reasons why this $\mathrm{RC}$ has certain ranges are explained as follows: 1 . The conductivity in the A-V node changes continuously with the change in vagal nerve tonicity. 2. The preceding $R-R$ interval also has influences on the A-V conduction. 3. Some measuring errors might occur.

It was also shown that the RC was convex while the slope of the RC near the absolute refractory period became greater than 45 degrees in the majority of cases, although the slope remained less than 45 degrees in 1 case.

Hoffman explored the function of the $\mathrm{A}-\mathrm{V}$ node in canine hearts. ${ }^{8}$ ) After basic atrial stimulation, another testing premature atrial stimulation was given at various coupling periods. The slope of the recovery curve obtained by this method also became greater than 45 degrees near the absolute refractory period in the majority of the cases, but remained less than 45 degrees in a few cases. It is interesting that in this study, with a slightly different method, the same 2 types of $\mathrm{RC}$ were obtained in human hearts as Hoffman obtained in his study of canine hearts.

Assuming that $\mathrm{P}^{\prime} \mathrm{V}$ is a function of the preceding $\mathrm{VP}^{\prime}$ and the curve representing $P^{\prime} V=f\left(V P^{\prime}\right)$ has the shape as described above, the mechanism of the Wenckebach periodicity during AP and the development of various types in the manner of increment change will be explained as follows. In Fig. $7 \mathrm{~A}, 7 \mathrm{~B}, 7 \mathrm{G}$ the curvilinear lines represent the recovery curve $\left(\mathrm{P}^{\prime} \mathrm{V}=\mathrm{f}\left(\mathrm{VP}^{\prime}\right)\right)$

A
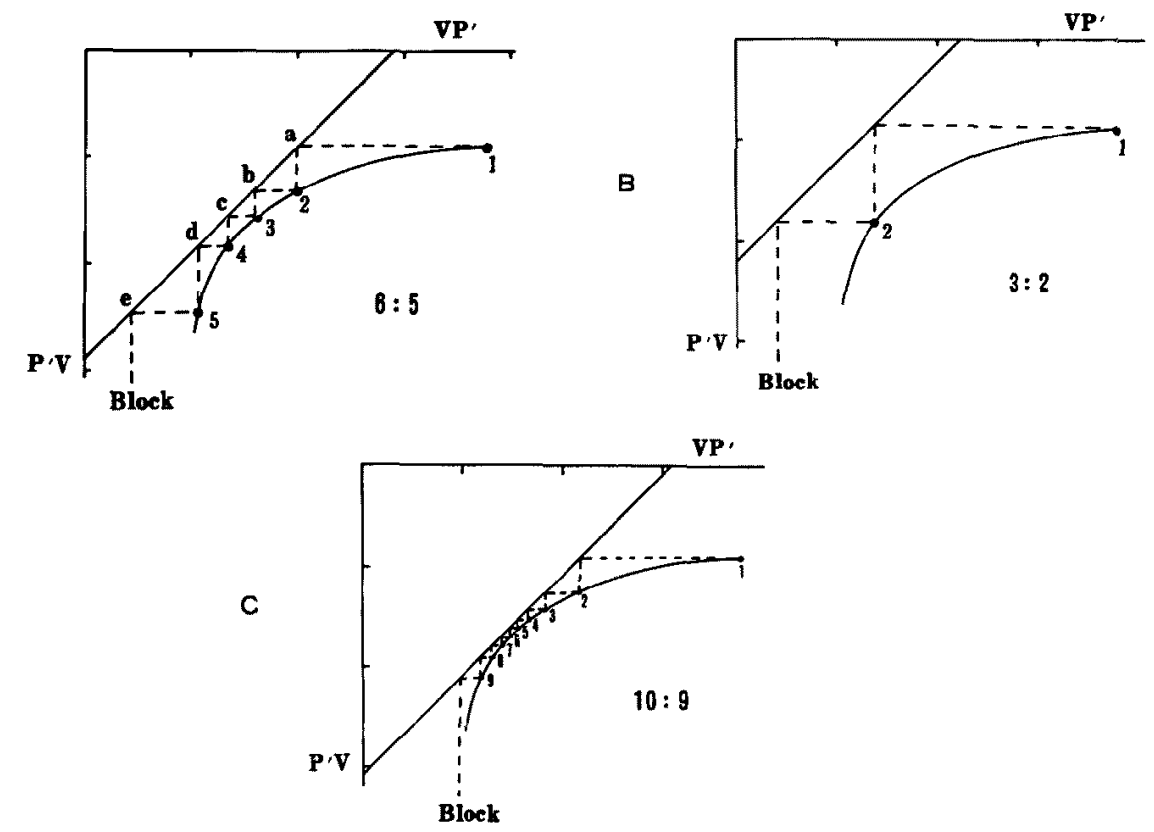

Fig. 7. An analysis of Wenckebach periodicity during atrial pacing. 
and the diagonal lines represent the relationship of $\mathbf{P}^{\prime} \mathbf{P}^{\prime}=\mathbf{P}^{\prime} V+V \mathbf{P}^{\prime}$. Fig. 7-A is a schema which shows the mechanism of the WP when AP is done at the pacing interval in which the diagonal line is shown as being moderately apart from the RC. The first $\mathrm{P}^{\prime} \mathrm{V}$ after the block is shown by the point 1 . The following VP' is shown by point " $a$ " which is the intersection of the horizontal line from point 1 and the diagonal line. At this $\mathrm{VP}^{\prime}$ interval, the next $\mathrm{P}^{\prime} \mathrm{V}$ interval is represented by point 2 which is the intersection of the vertical line from point " $\mathrm{a}$ " and the RC. In the same manner, the following $V^{\prime}$ ' and $P^{\prime} V$ intervals are shown by points $b, 3, c, 4, d$, and 5 . When the VP' becomes " $\mathrm{e}$ ", it is in the absolute refractory period. Therefore an A-V block develops. At a more frequent pacing rate, the diagonal line moves toward the left. Although, strictly speaking, the $\mathrm{RC}$ also shifts as the pacing rate is changed, the shift seemed to be negligible as shown in actual cases. Then the diagonal line separates in distance away from the $\mathrm{RC}$ as shown in Fig. 7-B. In this situation, the Wenckebach period with a low conduction ratio inevitably develops. On the other hand, when the diagonal line positioned near the recovery curve at a longer $\mathbf{P}^{\prime} \mathbf{P}^{\prime}$ interval, the Wenckebach period with a high conduction ratio develops as shown in Fig. 7-C. In Fig. 7-A, the distance of a-2, b-3, c-4, and d-5 represents the increment of the $\mathrm{P}^{\prime} \mathrm{V}$ prolongation. When the slope between 2 points is less than 45 degrees as the slope between points 2 and 3; the increment decreases because b- 3 is shorter than a-2. And the increment of the 5 th beat is greater than the one of the 4 th beat because the slope between points 4 and 5 is greater than 45 degrees.

Now, on the basis of the mechanism of the WP as described above, the development of each type in the WP is thought to be explained in the following way (Fig. 8). In those instances of a type $B$ recovery curve, the WP becomes type $I$ at any conduction ratio as shown in Fig. 8-A and 8-B because the slope between 2 points is less than 45 degrees at any part of the recovery curve. In those instances of a type $A$ recovery curve, the WP has a tendency to become type I at a low conduction ratio (Fig. 8-C), but it becomes type II at a higher conduction ratio because the last 2 beats have a greater chance to drop on the recovery curve after the slope becomes greater than 45 degrees, (Fig. 8-D). The type III period is understood to develop when the slope between the second and the third points is more than 45 degrees (Fig. 8-E). The type IV period develops only when the slope between the second and the third points becomes 45 degrees by chance occurrence. Therefore, the type of the WP is understood to be determined by the relationship between the shape of the recovery curve and the pacing rate at which the period develops. In other words, the mechanism of the development of these 4 types of WPs is 

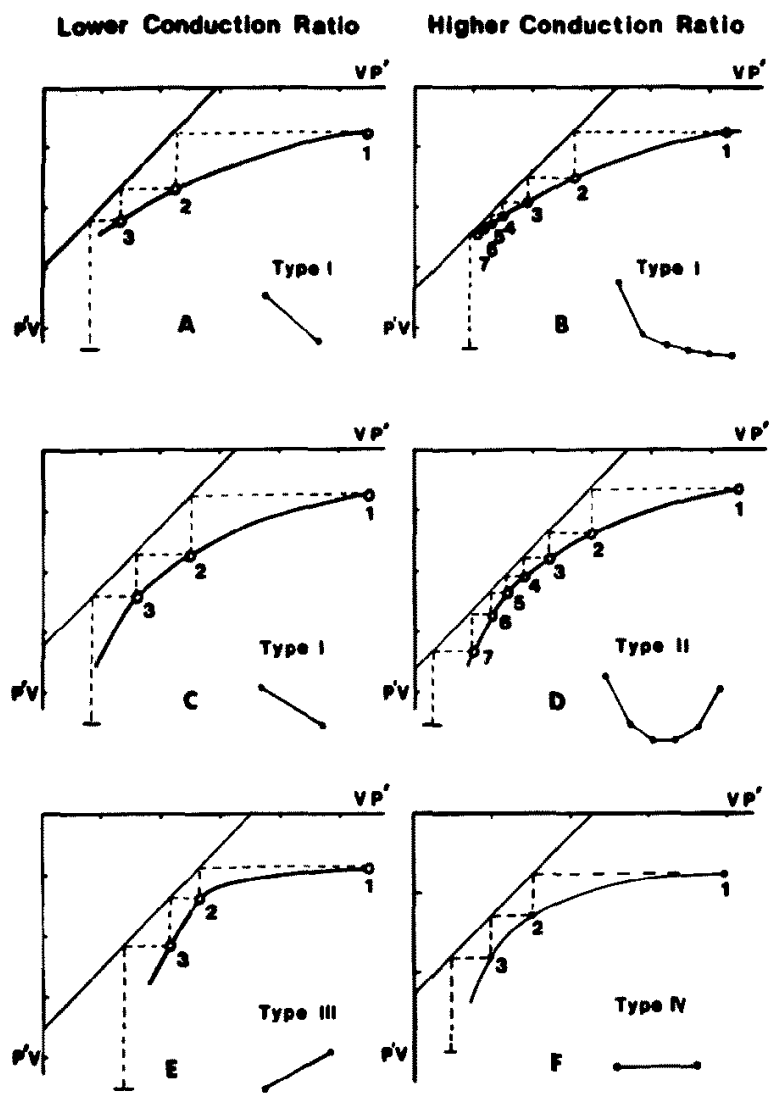

Fig. 8. The mechanism by which various types of Wenckebach period develop.

not fundamentally different.

In actual cases, it is understandable that the increments fluctuate a little in the area where the diagonal line comes near the recovery curve because the $\mathrm{RC}$ shifts a little from time to time. This is the reason why these minor fluctuations of the increments were neglected in determining the type of WP with high conduction ratios.

The type V WP in Fig. 1 has been explained by the supernormal conduction theory. ${ }^{7)}$ Since the type V WP was experienced only once in the present study the mechanism of this type is not mentioned.

Levy et al has already explained the mechanism of the WP by what he has called the "positive feedback theory", because the mechanism resembles a positive feedback system." The data from the present study give clinical evidences to support this theory.

Finally the present study does not define the electrophysiological mechanism in the A-V node which produces these various types of WPs. Further 
study is necessary to define the relationship between the present study and the detailed electrophysiological study of the A-V node which Watanabe ${ }^{10), 11}$ and Hoffman ${ }^{8)}$ and other authors have done.

\section{ACKNOWLEDGEMENTS}

Grateful acknowledgement is made to Dr, Kazuhiko Katayama, Chief of Cardiology Division, and Drs. Takanori Ogino, Mitsuru Kimura, Takamitsu Oikawa, and other collegues of Cardiology Division, Department of Internal Medicine, Saiseikai Central Hospital, for their guidance and collaboration.

\section{REFERENCES}

1. Castillo $\mathrm{C}, \mathrm{Martin} \mathrm{O}$, Castellanos $\mathrm{AJr}$ : His bundle recordings in atypical A-V nodal Wenckebach block during cardiac pacing. Am J Cardiol 27: 570, 1971

2. Denes P, Lawrence L, Pick A, Rosen KM: The incidence of typical and atypical A-V Wenckebach periodicity. Am Heart J 89: 26, 1975

3. Ito A, Shinoda S, Nagashima $\mathbf{M}$, Tanno $\mathbf{M}$ : Pacing induced Wenckebach periods, studies with His bundle electrogram. Resp Circulat 23: 61, 1975 (in Japanese)

4. Friedman HS, Gomes JAC, Haft JI: An analysis of Wenckebach periodicity. J Electrocardiol 8: 307, 1975

5. Scherlag GJ, Law SH, Helfant RH, Berkowisz WD, Stein E, Damato AN: Catheter technique for recording His bundle activity in man. Circulation 39: 13, 1969

6. Abernathy WS: A rare form of Wenckebach atrioventricular block. J Electrocardiography 7: 183,1974

7. Sherf $D$, Schott A: The supernormal phase of recovery in man. Am Heart J 17: 357, 1939

8. Hoffman BF, Moore EN, Stuckey JH, Cranefield PF: Functional properties of the atrioventricular conduction system. Circulat Res 13: 308, 1963

9. Levy MN, Martin PJ, Edelstein J, Goldberg LB: The AV nodal Wenckebach phenomenon as a positive feedback mechanism. Prog Cardiovasc Dis 16: 601, 1974

10. Watanabe Y, Dreifus LS: Second degree atrioventricular block. Cardiovasc Res 1: 150, 1967

11. Watanabe Y, Dreifus LS: Inhomogeneous conduction in the A-V node. Am Heart J 70: 505,1965 